International Journal of Health, 5(1)(2017) $1-11$
Website: $\begin{gathered}\text { www.sciencepubco.com/index.php/IJH } \\ \text { doi: } 10.14419 / \text { ijh.v5il.6893 } \\ \text { Research paper }\end{gathered}$
SPC

\title{
School dropout among orphans in Oshana region - Namibia
}

\author{
Anthony Shanuolu Ishola ${ }^{1 *}$, Kabwebwe Honoré Mitonga ${ }^{2}$ \\ ${ }^{1}$ University of Namibia, Faculty of Health Sciences, School of Pharmacy \\ ${ }^{2}$ University of Namibia, Faculty of Health Sciences, School of Public Health \\ *Corresponding author E-mail:aishola@unam.na
}

\begin{abstract}
This research seeks to investigate why some orphaned children drop out of school in Oshana region, Namibia, despite concerted efforts by the Government Republic of Namibia and other stake holders to keep them at school.

The study aimed to identify the indicators preceding AIDS orphaned children dropping out of schools in the Oshana region-Namibia. A cross-sectional study, which adopted both quantitative and qualitative approaches, was used to gain a complete picture of the situation of orphans and school dropouts from the perspective of school teachers, learners, and orphans who have already dropped out of school. It was found that many orphans still face many challenges and to some, continuing with schooling is a luxury that is ill afforded. The total percentages of learners that dropped out of school are: 52.9\% orphans in grades 7 and 8 in 2009 while $41.7 \%$ dropped out in 2010. Poor awareness of Government support initiatives, poor psychosocial support, leaving school to grieve the death of a parent and working to earn income, ranked amongst the highest reasons some orphans dropped out of school. Provision of material resources in addition to human torch as demonstrated by majority of life skill teachers towards the well-being of AIDS orphans have greatly ameliorated the self-worth and schooling of orphans.
\end{abstract}

Keywords: School Dropout; Orphans; OVC; HIV/AIDS; Oshana Region; Namibia.

\section{Introduction}

\subsection{Background and rationale}

AIDS is a global public health and medical crisis, particularly for the people of sub-Saharan Africa. Ssewamala (2008) reported that, in Uganda, for example, over 1 million children have lost one or both parents due to HIV/AIDS. Facing multiple problems, AIDS orphans are in need of responsive interventions to them from HIV infection and advance their educational and economic futures.
For a variety of reasons, little attention has been paid to the situation of children affected by HIV/AIDS. Greater understanding of the impact of HIV/AIDS on children is important in the design and evaluation of programmes to support children living in difficult circumstances.

One key intervention strategy to ameliorate the impact of HIV/AIDS on orphans and to empower them is through education. However, this intervention on its own is not yielding the desired goals as more orphans are dropping out of school. A research carried out by UNICEF (2003) shows that from 1990 up to 2010, more AIDS orphans dropped out of school than Non-AIDS orphans.

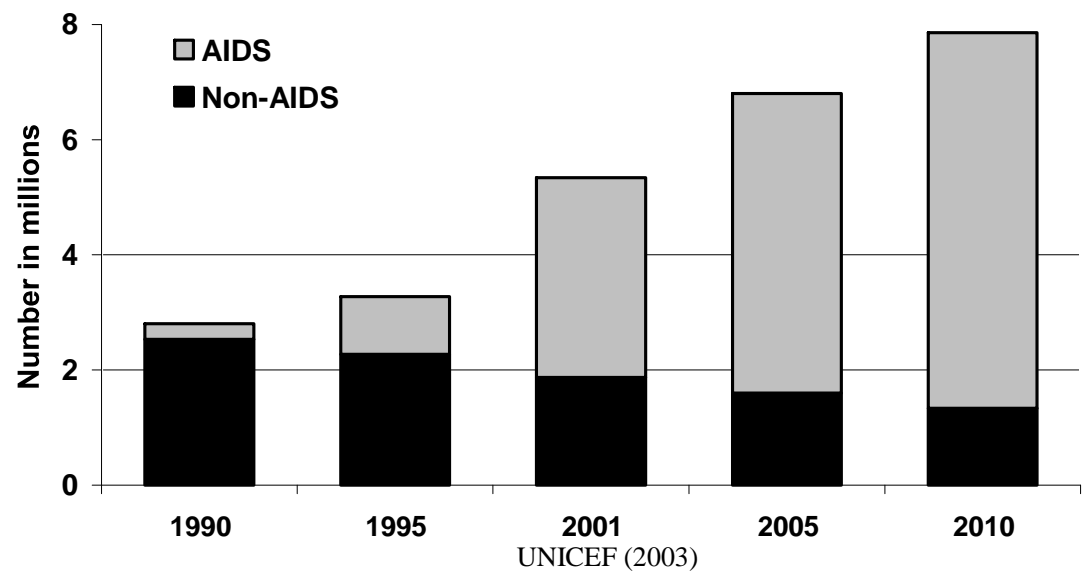


If the trend depicted above is not halted, HIV/AIDS pandemic has the potentials to pose a serious threat to reaching the Education for All goals set for 2015 in Namibia.

The death rate in the Oshana Region is one of the highest in the country. This has undoubtedly, as observed by Mchombu (2009), given rise to high numbers of orphans in the region, which was estimated to be approximately 14773 . As the number of orphans is on the increase, it follows that school attendance will likely fall. Identifying the factors that compound school dropout will enable relevant authorities to put measures in place to mitigate school dropout amongst orphans in the region. Therefore, the researchers set before themselves to investigate the factors that lead to orphans dropping out of school in the Oshana region of Namibia.

\subsection{Literature review}

Of the children orphaned by AIDS throughout the world, 95\% have lived in Africa, where the numbers of orphans is expected to rise through the next decade reaching 40 million. (Forster, 2000). With a population of about 2.1 million, Namibia has an estimated 250,000 orphaned and vulnerable children (OVC), (Namibia National Planning Commission and United Nations, 2005) which represent a prevalence of about $12 \%$. Amongst orphans, $60 \%$ have been orphaned by AIDS, UNAIDS/WHO (2008). Oshana region is one of the thirteen regions in Namibia, and is home to approximately $14.2 \%$ AIDS orphans (Mchombu 2009). Most children in the country - approximately 247,400 , more than a tenth of the Namibian population - are vulnerable or orphaned, many of them because of AIDS. In Namibia, the ratio of orphans to non-orphans aged 10 to 14 attending school was $0.92,0.97,1.0$ and 1.01 in 2003, 2005, 2007 and 2009 respectively (Mchombu, 2009). The above observation is consistent with the trend found in other African countries showing the likelihood to attend school by HIV status (Eric, 2003).

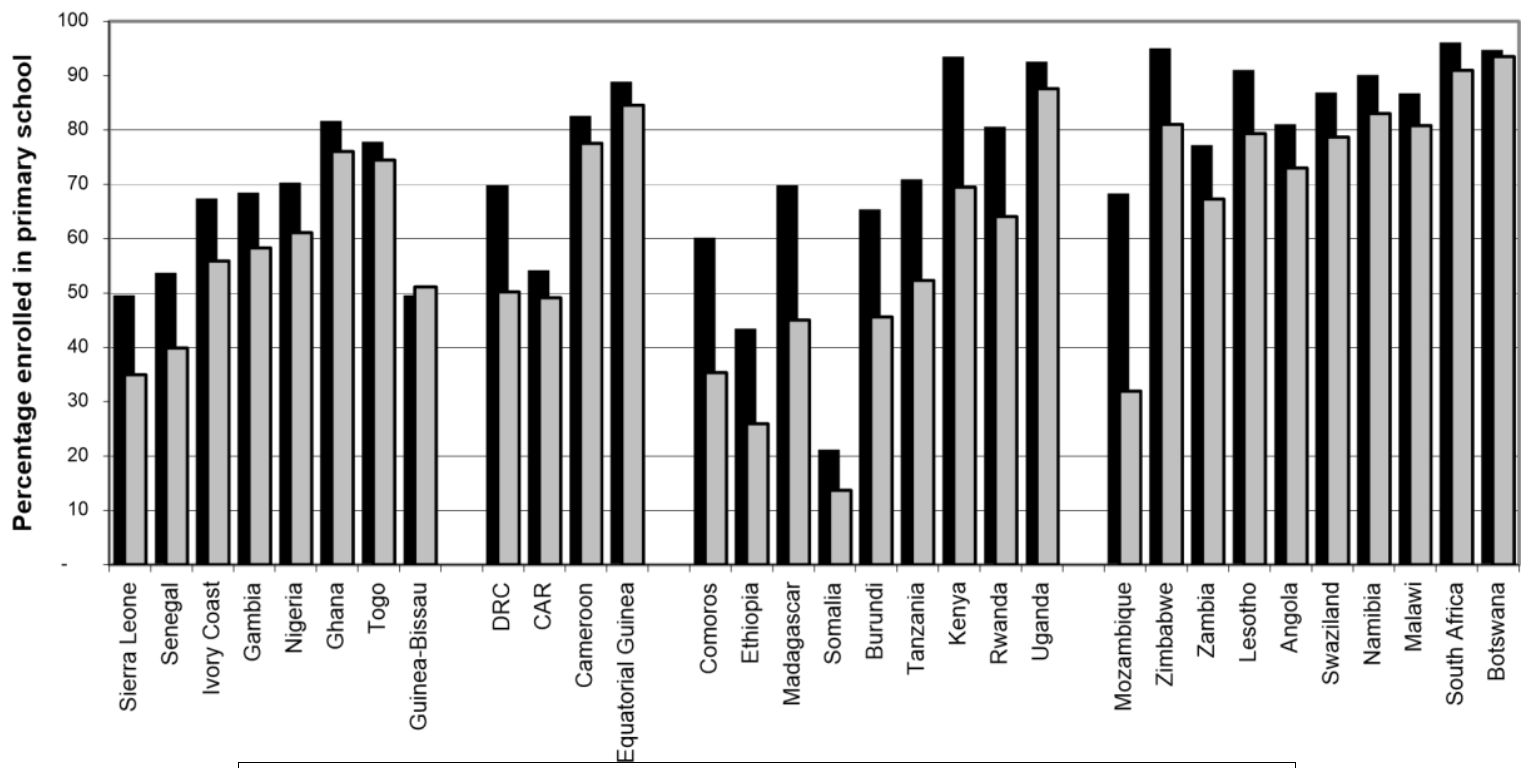

- Non-orphans (living with at least one parent) aDouble orphans

Fig. 1: Percentage of Orphans Enrolled in Primary Schools in African Countries.

The United Nations Children's Fund (UNICEF) estimated that around $60 \%$ of OVC in Namibia are being raised by their grandparents (Biemba et al., 2009). Extended families often face financial and other burdens as they strain to meet the needs of the children in their care. The HIV/AIDS pandemic is observed to have weakened the extended family support system as the number of orphans increased. This has led to increased numbers of working children, children who dropped out from schooling to provide care and orphaned street children. According to UNICEF (2003), there is a need to understand the reasons why children slip through the extended family safety net.

According to Kinghorn et al. (2002), orphaned children in general have less access to education and health care, they also have more indicators of psychosocial distress, and faces greater degrees of child neglect, abandonment, and abuse when compared to non-orphans. UNAIDS (2009) observed that “... neglect of millions of children affected by HIV/AIDS (orphans) is fuelling school dropout across East and Southern Africa."

Cases and his colleagues as cited by Richter (2004) argued that orphaned children who are fostered are at a distinct disadvantage in that they are less likely to attend school than co-resident in the household as they are made to do all the home chores.

In sub-Saharan Africa, there are more than 12 million children orphaned by AIDS, and this number does not include the millions of children whose parents are terminally ill. While overall school enrolment rates have risen to approximately $66 \%$ in the continent
AIDS-affected children have been systematically left behind. The magnitude of OVC in Namibia is estimated to consists of Orphans and Vulnerable Children in Namibia about 263,000 (Ministry of Health and Social Services (MoHSS). The number of Orphans in Namibia is about 140,000 while children orphaned by HIV/AIDS is about 66,000 (UNAIDS, 2009).

Dropout from school or failure to enrol is the clearest manifestation of impacts of orphans on education. According to Kinghorn (2002) international evidence indicates that orphans tend to have lower enrolment rates than children with both parents alive and the poor enrolment can be considerable - around 30\% lower or worse. Impacts seem to vary widely, depending on social, economic and cultural circumstances. Household income may be a stronger predictor of non-enrolment than orphan status per se. Kinghorn (2002) also reported that poverty forces many children to drop out of school. He reported that girls are more likely than boys to drop out of school or be forced to stay home because of financial limitations. Amongst children 15-19 years whose parents had died, only $29 \%$ continued their schooling undisrupted; $25 \%$ lost school time and 45\% dropped out of school; those fostered by grandparents had the least chance (7\%) (Eric, 2003).

In Namibia, there is limited data on orphan drop out and attendance rates. However, there are strong indications from qualitative work and school survey that a significant number of orphans are affected by drop out. In a research conducted by Human Rights Watch, 29 $\%$ of the learners sampled knew children who had dropped out of 
school for over a month after a parental death and $26 \%$ knew of permanent drop outs after parental death. As reported in Burns (2001), previous survey found that significant numbers of drop outs, independent of HIV/AIDS, are due to factors associated directly or indirectly with levels of parental support, and this is a cause for concern.

Children leave school to perform household labour or to grieve their parents' death. Many do not return to school as they can no longer afford school fees because their surviving parent is too sick to earn a living or their grandparents or foster parents cannot afford school development fees and uniform. Dropping out of school exposes orphans to a lifelong cycle of poverty and abuse. Children who dropped out of school faces a high risk of sexual exploitation, hazardous labour, and living in the street. Orphans have reduced demand for education in several ways; the loss of wage earners in the family can reduce it to poverty. Supporting the direct and indirect costs of education becomes increasingly difficult as medical and funeral expenses absorb family resources. Human Rights Watch has mentioned that surveys in highly AIDS-affected areas in numerous countries have found that orphans are less likely to attend school than non-orphans; less likely to be at the appropriate grade given their ages; and more likely to have their schooling interrupted. In 2003, based on demographic data from thirty-one countries, and reported by Human Right Watch and UNICEF, they concluded that "orphans are less likely to be in school and more likely to fall behind and dropout". However, it is not just the lack of financial resources that will keep orphaned children out of school. Even if orphaned children enter school, the chances of them completing their education are slim. This is due to the fact that many of them will need to work or care for sick adults or look after younger siblings. They may also be ostracized, discriminated against and suffer from stigma when it is known that their family members have HIV/AIDS. About $50 \%$ of orphans in Namibia are AIDS related, for ethical reasons and to avoid discrimination and stigmatization, we considered not to isolate AIDS orphans from the general orphans' population in the Region under review. So in this study, no distinction is made between AIDS orphans and orphans from other causes.

There is paucity in researches involving school dropout among orphans in Namibia, therefore it is relevant for us to conduct an assessment of various indicators of school dropout from teachers, learners and orphans perspectives.

Objective of the study

The main objective of this study is to identify the indicators preceding orphaned children dropping out of schools in Oshana region in order to develop tools to reduce school dropout.

Specific Objectives

To identify various indicators for school dropout from principals / teachers perspectives. Identify various indicators for school dropout from perspectives of learners and orphans who already dropped out of their schools and to make recommendations to stakeholders on how to reduce school dropout amongst orphans in Oshana region of Namibia.

\section{Methodology}

\subsection{Data collection}

This is a cross-sectional study which adopted both quantitative and qualitative research approaches. Data on the trend of orphans' dropout in 2009 and 2010 were collected from different schools for grade 7 and 8 .

In order to give answers to the topic, the researchers targeted the three populations: professional teachers, orphans that are still at school and orphans who already dropped out of school.

Questionnaires-based survey was conducted amongst school children and learners who dropped out of school and key informants (i.e. Schools teachers and principals) using qualitative and quantitative data collection methods concurrently.
A samples of 780 school children from 9 schools and 27 teachers and principals were selected.

A structured scaled 32-items questionnaire was used to collect data. In fact, the questionnaire comprised mainly closed ended questions. The respondents were required to state their agreement or disagreement on each statement by selecting the following scales: Strongly Agree, Agree, Indifferent, Disagree, and Strongly Disagree.

In order to gain insight into the links between being an orphan and the tendency to drop out of school and insight into the support systems that are available to assist orphans in coping with the challenges of being an orphan, the researchers organised a focus group discussion with orphans who dropped out of school.

The selection criteria for inclusion in this study were based on the three populations of the study as follows:

\subsection{Sampling criteria for teachers}

Two Life Skills teachers and a principal from each of the sampled schools provided ample insight into the situation of orphans at the different schools. They had to be primary school or junior secondary teachers, they have taught life Skills as a subject for at least two years and they work directly with orphans at the school in addition to their willingness to participate in the exercise. The respondents for the questionnaire had to be able to self-administer the instrument and return it to the researchers through the respective headmaster of the school.

\subsection{Sampling criteria for school children}

The children had to be in primary or junior secondary school, and be in grade 7 or 8 and not older than eighteen (18) years. This is because orphans are generally defined as children under 18 who have lost one or both parents and or a care giver. The cut age of eighteen is also of significance; an eighteen years old learner still in a junior secondary school may likely be an orphan who is behind in his or her grade. This is also the most vulnerable age for an orphan; he or she is completely dependent upon direct or indirect support for survival and or schooling UNICEF, (2005). Consent for the children to participate was first discussed with the children, when they accepted the parents or guardians were asked to give and sign consent forms on their behalf.

\subsection{Sampling criteria for orphans who dropped out of school}

The children in this category are boys and girls under 18 years who are not attending school. However, it was difficult to have a good number of them at a particular time. The researchers administered the focus group discussion on one on one basis. This has the advantage of protecting the identity of the participants. These are mostly street kids, children hawkers, domestic workers and gardeners.

\subsection{Ethical clearance}

Ethical permission to conduct this research was obtained from University of Stellenbosch, Ethical committee. Permission to conduct this research at upper primary and junior secondary schools was obtained from the Permanent Secretary of the Ministry of Education, Windhoek. Permission to visit schools in Oshana region was given by the Regional Director of Oshana Region. Permission was granted by the principals of the respective schools. Although learners were randomly selected from a pool of orphans, they were informed that their participation was voluntary and that they were free to withdraw from the exercise at any point without any consequence.

Guardians of all learners who participated gave their informed consents for their ward to participate in the research. 


\subsection{Data analysis}

Proportions were used to summarize various indicators for school dropout from principals / teachers perspectives, from learners and orphans who already dropped out of schools perspectives.

Nine schools were randomly selected to participate in this study. All orphans in the 9 selected schools in 2010 received a questionnaire. Two hundred and forty, representing $86.6 \%$ responses were completed and returned.

Orphans at schools who responded to the questionnaire are fairly balanced in gender, $45 \%$ male and $55 \%$ females completed the questionnaires. $37.5 \%$ and $62.5 \%$ males and females respectively of orphans out of a pool of 24 who already dropped out of school participated in the focus group interview. $70.4 \%$ principals and Life Skills teachers who completed the questionnaires are females while the remaining $29.6 \%$ are males.

\section{Results}

The tables presented below contain information obtained from records of the nine schools where questionnaires were administered. Only grades 7 and 8 participated in this report.

Table 1 and 2 shows the trend of the number of learners in grade 7 and 8 of the sampled schools. The percentages of AIDS orphans in each grade are presented. The number of learners per grade who dropped out of school is presented alongside number of AIDS orphans who dropped out of school from all schools that participated in the research. From tables 1 and 2, the percentage of orphans who dropped out of school in 2009 and 2010 were considered; $52.9 \%$ of them are orphans in grades 7 and 8 in 2009 while $41.7 \%$ dropped out in 2010. These are percentages of all learners who dropped out of school during 2009 and 2010. Some individual schools have worse percentages of orphans who dropped out of school in the two years under consideration.

Table 1: Percentage of School Dropout amongst Grade 7 and 8 Orphans in Participating Schools in Oshana Region in 2009

\begin{tabular}{|c|c|c|c|c|c|c|c|}
\hline Schools 2009 & $\begin{array}{l}\text { Grad } \\
\mathrm{e}\end{array}$ & $\begin{array}{l}\text { Learn- } \\
\text { ers }\end{array}$ & $\begin{array}{l}\text { Or- } \\
\text { phans }\end{array}$ & $\begin{array}{l}\% \text { of or- } \\
\text { phans }\end{array}$ & $\begin{array}{l}\text { Total \# learners who left } \\
\text { school }\end{array}$ & $\begin{array}{l}\text { \# of Orphans who left } \\
\text { school }\end{array}$ & $\begin{array}{l}\% \text { of orphans who left } \\
\text { school }\end{array}$ \\
\hline Ambili CS & 7 & 112 & 38 & 33.9 & 2 & 1 & 50.0 \\
\hline $\begin{array}{l}\text { Andimba TYT } \\
\text { SSS }\end{array}$ & 8 & 57 & 17 & 29.8 & 0 & 0 & 0.0 \\
\hline Iihenda SSS & 8 & 180 & 48 & 26.7 & 6 & 4 & 66.7 \\
\hline Mvula JSS & 8 & 71 & 29 & 40.8 & 0 & 0 & 0.0 \\
\hline Nangolo SSS & 8 & 65 & 25 & 38.5 & 1 & 1 & 100.0 \\
\hline Olukol JSS & 8 & 102 & 2 & 2.0 & 5 & 1 & 20.0 \\
\hline Olukolo PS & 7 & 100 & 38 & 38.0 & 2 & 1 & 50.0 \\
\hline Oluno PS & 7 & 75 & 22 & 29.3 & 0 & 0 & 0.0 \\
\hline Oshitayi PS & 7 & 110 & 52 & 47.3 & 1 & 1 & 100.0 \\
\hline TOTAL & & 872 & 271 & 31.1 & 17 & 9 & 52.9 \\
\hline
\end{tabular}

Table 2: Percentage of School Dropout amongst Grade 7 And 8 Orphans in Participating Schools in Oshana Region in 2010

\begin{tabular}{|c|c|c|c|c|c|c|c|}
\hline Schools 2010 & $\begin{array}{l}\text { Grad } \\
\text { e }\end{array}$ & $\begin{array}{l}\text { Learn- } \\
\text { ers }\end{array}$ & $\begin{array}{l}\text { Or- } \\
\text { phans }\end{array}$ & $\begin{array}{l}\% \text { of or- } \\
\text { phans }\end{array}$ & $\begin{array}{l}\text { Total \# learners who Left } \\
\text { school }\end{array}$ & $\begin{array}{l}\text { \# of Orphans who left } \\
\text { school }\end{array}$ & $\begin{array}{l}\% \text { of orphans who left } \\
\text { school }\end{array}$ \\
\hline Ambili CS & 7 & 80 & 36 & 45.0 & 1 & 0 & 0.0 \\
\hline $\begin{array}{l}\text { Andimba TYT } \\
\text { SSS }\end{array}$ & 8 & 56 & 15 & 26.8 & 0 & 0 & 0.0 \\
\hline Iihenda SSS & 8 & 138 & 52 & 37.7 & 9 & 4 & 44.4 \\
\hline Mvula JSS & 8 & 103 & 36 & 35.0 & 3 & 1 & 33.3 \\
\hline Nangolo SSS & 8 & 46 & 27 & 58.7 & 1 & 1 & 100.0 \\
\hline Olukolo JSS & 8 & 74 & 18 & 24.3 & 4 & 1 & 25.0 \\
\hline Olukolo PS & 7 & 113 & 39 & 34.5 & 3 & 2 & 66.7 \\
\hline Oluno PS & 7 & 81 & 22 & 27.2 & 0 & 0 & 0.0 \\
\hline \multirow[t]{2}{*}{ Oshitayi PS } & 7 & 89 & 32 & 36.0 & 3 & 1 & 33.3 \\
\hline & & 780 & 277 & 35.5 & 24 & 10 & 41.7 \\
\hline
\end{tabular}

\subsection{Lack of support as a key drop out indicator}

As shown in Table 3, parental death, child headed home, sickness, lost interest in schooling, working to earn a living, failing a grade and old age are the major contributory factors identified by our key informants as strong indicators leading to orphans dropping out of school in Oshana region.

240 responses were returned to the authors from the different schools that were sampled. Orphans attending school identified lack of support as a major indicator for orphans to drop out of school Figure 1 which represents upper primary and junior secondary schools responses on the importance of support to AIDS orphans as an indicator for school dropout. The result shows a $69.2 \%$ of 240 respondents (sum of agree to strongly agree) are in support of the importance or support to keep AIDS orphans in schools.

A continuation of the trend was also picked up in the focus group interview with orphans who already dropped out of school. All orphans who already dropped out of school identified lack of support as a key indicator fuelling orphans school dropout in the Oshana region.

\subsection{Poor psychosocial support}

The poor psychosocial support orphans get from their guardians was reflected in their level of happiness. Figure 2 shows a combined $61.2 \%$ of respondents agree to strongly agree that most street kids are orphans who dropped out of school. The results presented in figure 3 could be a window to understanding the dropout rate; a combined 68\% (agree to strongly agree) from the learners in upper primary and junior secondary schools agreed to the fact that orphans are not always happy in their new residences after the death of their parents. This state of affairs makes orphans very vulnerable and at the risk of irrational decisions, which might include dropping out of school.

The self-worth of AIDS orphans came out strongly as an indicator of school dropout. Figure 4 shows a combined $60.4 \%$ of the participants agree that other children are better than they. This state of inferiority combined with discrimination and stigmatization associated with HIV and AIDS proved to be one of the reasons AIDS orphans dropout of school.

As depicted in Figure 5, 47.5\% of upper primary and junior secondary schools respondents are not staying with their siblings. $7.5 \%$ of respondents remain neutral. 


\begin{tabular}{lll} 
& Table 3: Indicators of School Dropout \\
\hline Comments by principals and teachers & Number of times out of 27 & Percentage \\
\hline Too old for grade & 18 & 66,67 \\
Failure & 21 & 77,78 \\
Lost interest in schooling & 24 & 88,89 \\
Domestic problems & 20 & 74,07 \\
Lack of parental love/ guardian support & 20 & 74,07 \\
Work to earn income & 22 & 81,48 \\
Discipline & 12 & 44,44 \\
Child headed home & 25 & \\
Substance abuse & 14 & \\
Relocation of guardian & 18 & \\
Sickness & 24 & \\
Parental death & 27 & 66,59 \\
\end{tabular}

\section{Street kids left school because there is no one to care for them}

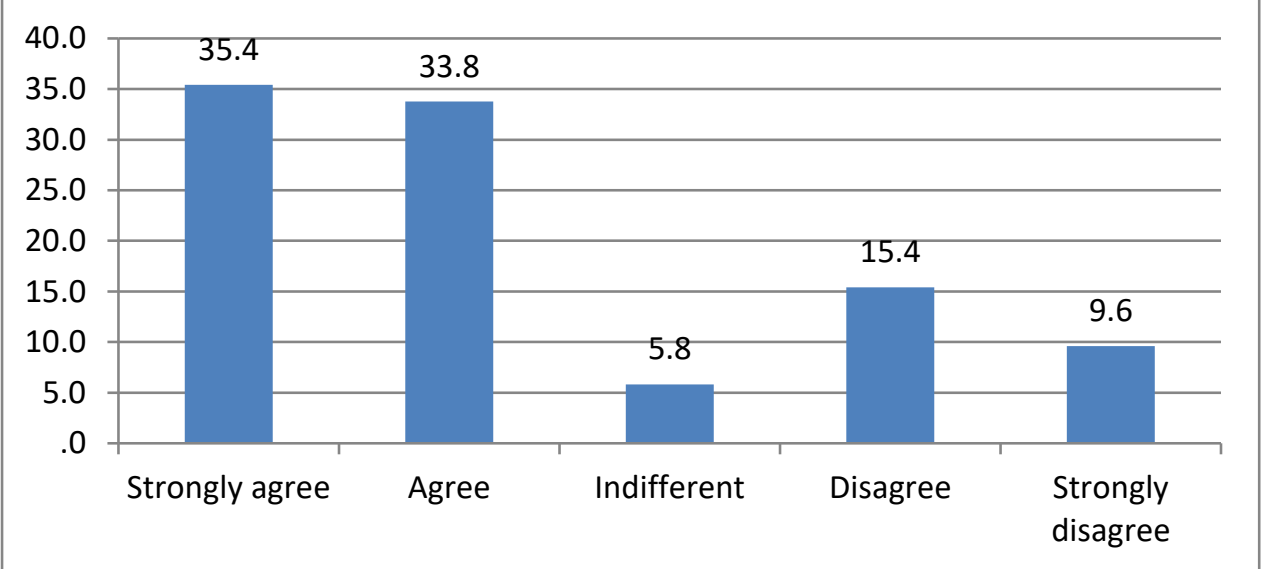

Fig. 2: Street Kids Left Because There Is No One to Care for Them.

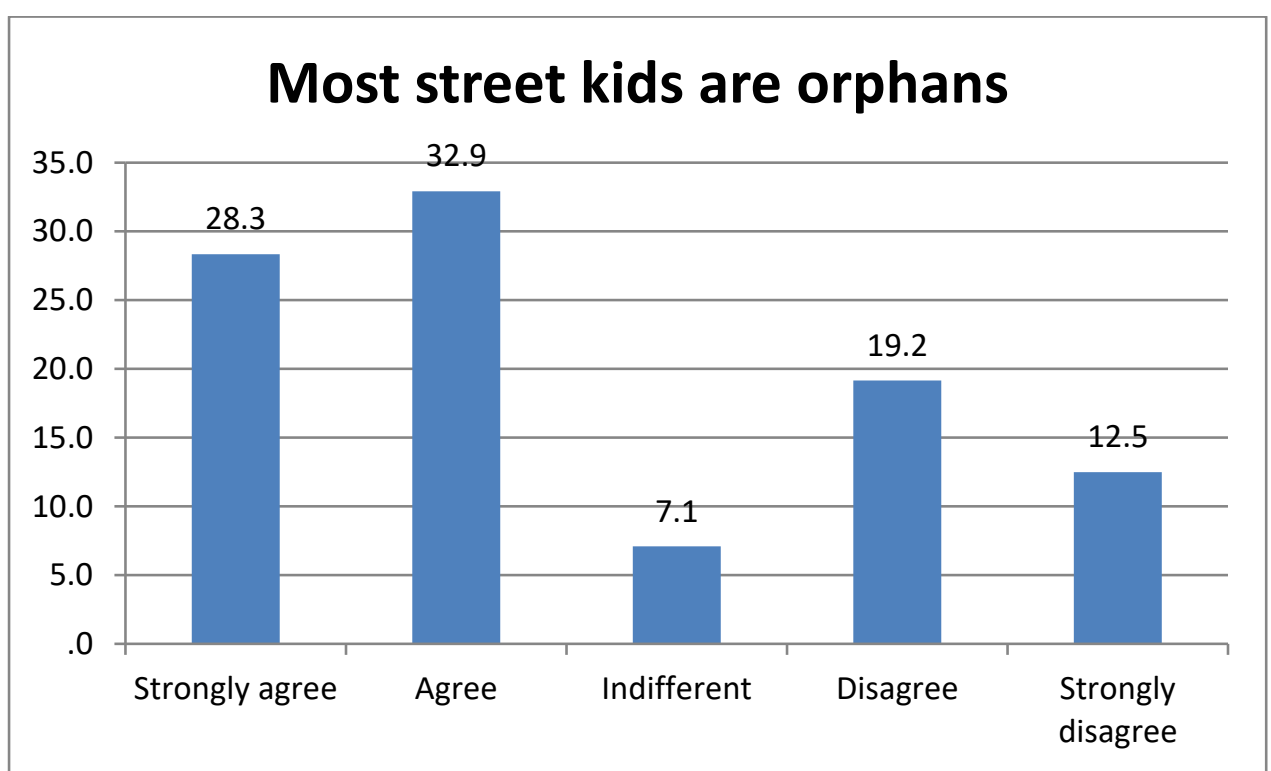

Fig. 3: Most Street Kids are Orphans. 


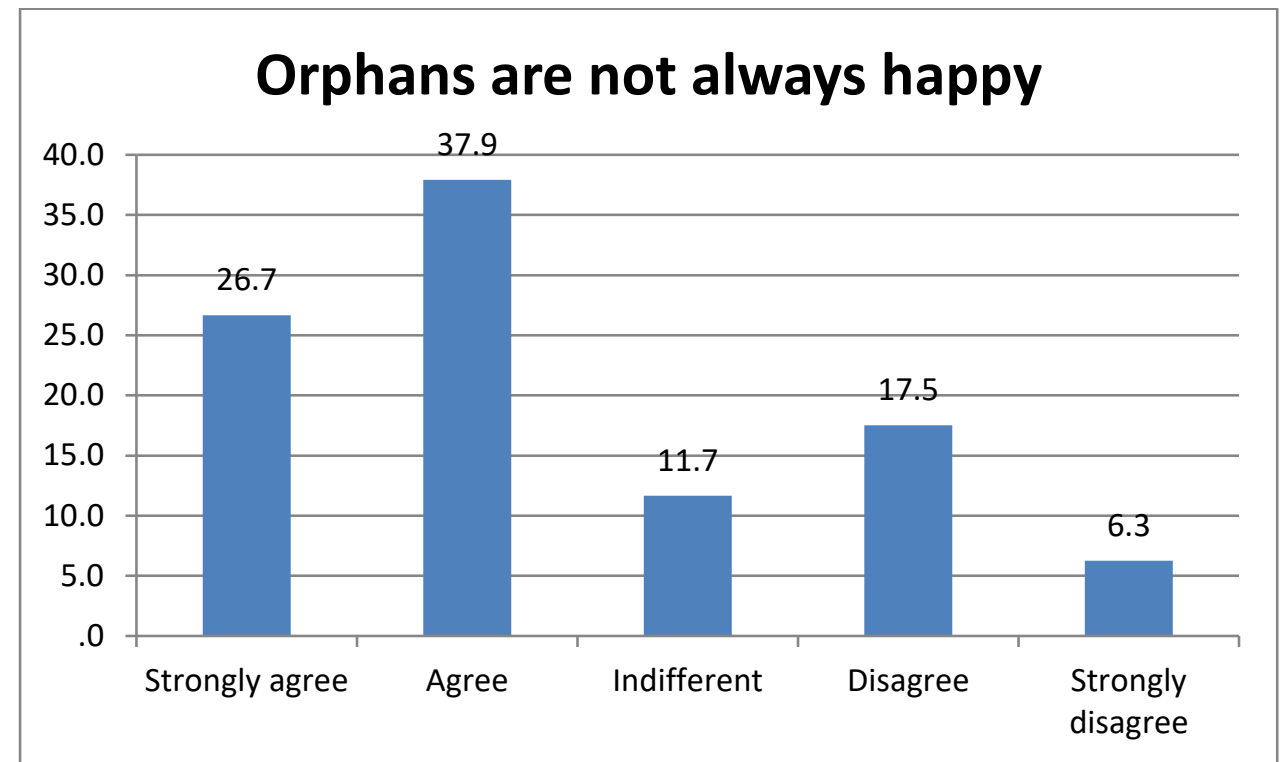

Fig. 4: Orphans are Not Always Happy.

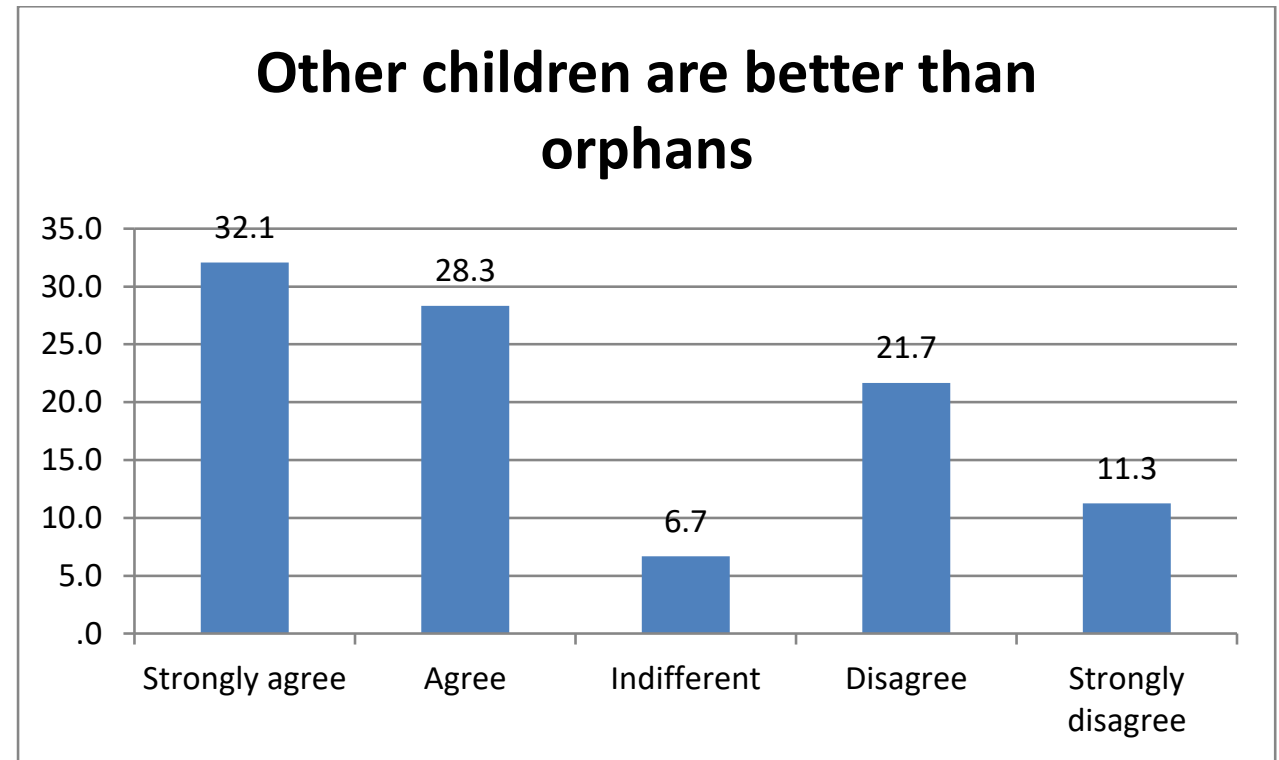

Fig. 5: Other Children are better than Orphans.

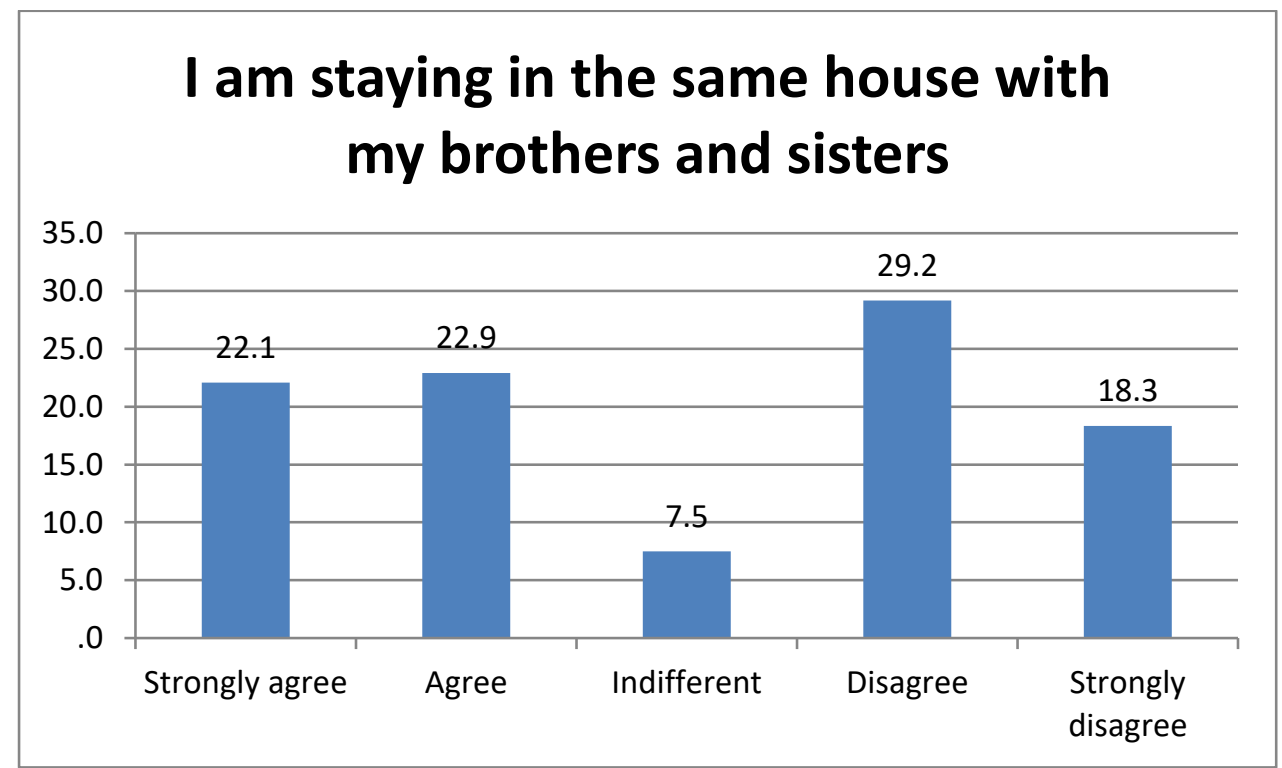

Fig. 6: I Am Staying in the Same House with My Brothers and Sisters. 
dropout. These included avoidance, teasing and neglect. Indications of inability to deal with psychosocial problems, such as lack of motivation, bad behaviour, social problems or substance abuse, though not specific to orphans, were also cited as reasons for drop out by teachers.

Orphans are also very lonely people; $63.3 \%$ of 240 upper primary and junior secondary schools subjects confirmed this assertion. This is not uncommon in a situation where there is discrimination and stigmatization. Figure 6 shows a cumulative $63.3 \%$ of all respondents in upper primary and junior secondary schools agreed that AIDS orphans sometimes feel very lonely. It also came out as a strong indicator amongst participants in the focus group interview. All of them concurred it was a contributory reason why they left school.

All participants from upper primary and junior secondary school who dropped out of school agreed that if there is one thing they wish to have, it is the return of their late parents. Leena who dropped out of school in grade 8 recalled that:
"I sit alone and cried when I think of the ways my mother used to support me and when I realised that she is never coming back"

"I wish that my mother will come back to life"

Poor access to social grant is fuelling school dropout; Figure 7 shows $75 \%$ of AIDS orphans who dropped out of school never heard of the availability of social grant to assist orphans with their education. All participants in the focus interview confirmed that hunger was a contributory factor why they left school. Figure 7 also shows that $42.1 \%$ upper primary and junior secondary school AIDS orphans agreed that hunger is a factor promoting school dropout. Table 3 shows that Principals and Life Skills teachers responded $81.5 \%$ of the time that orphans work to earn an income in order to feed themselves. An AIDS orphan who got this grant but still dropped out school recalled that:

"I am registered to get social grant to enable me continue my schooling, but when the money is collected, it is used to secure food for the whole family"

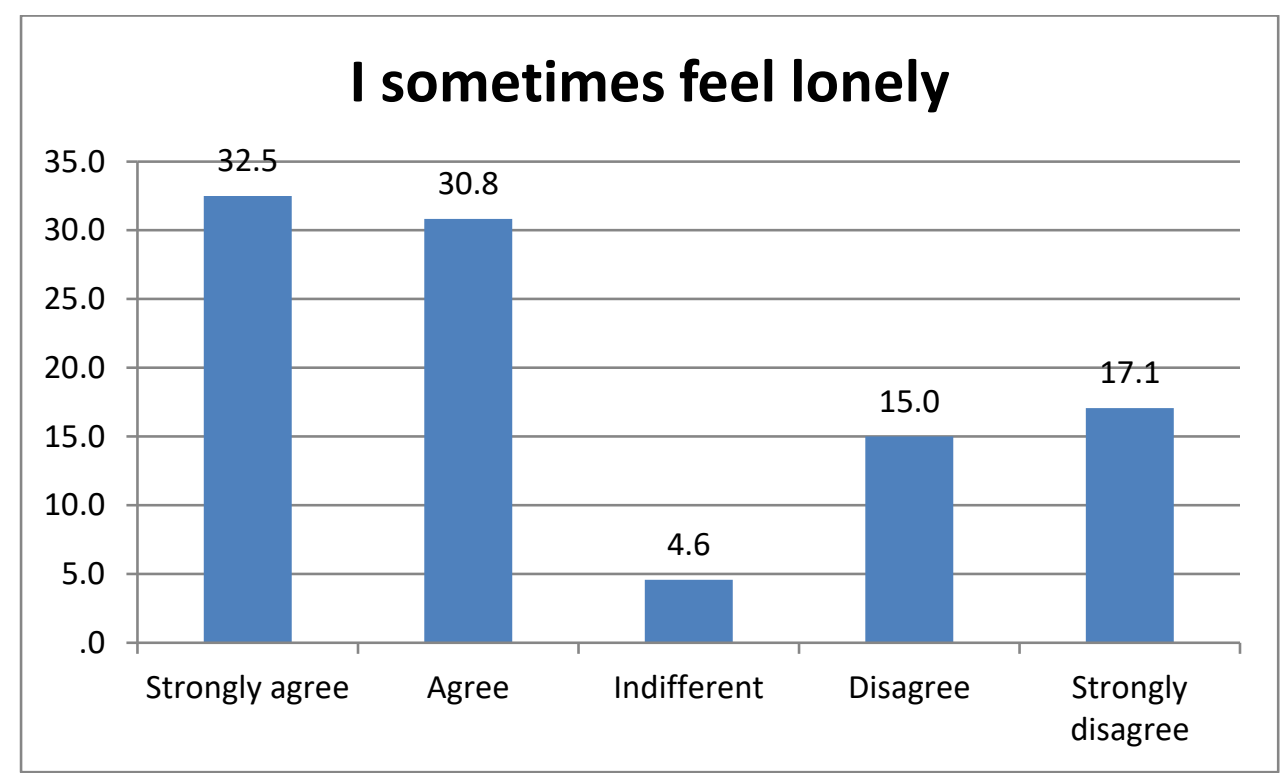

Fig. 7: I Sometimes Feel Lonely.

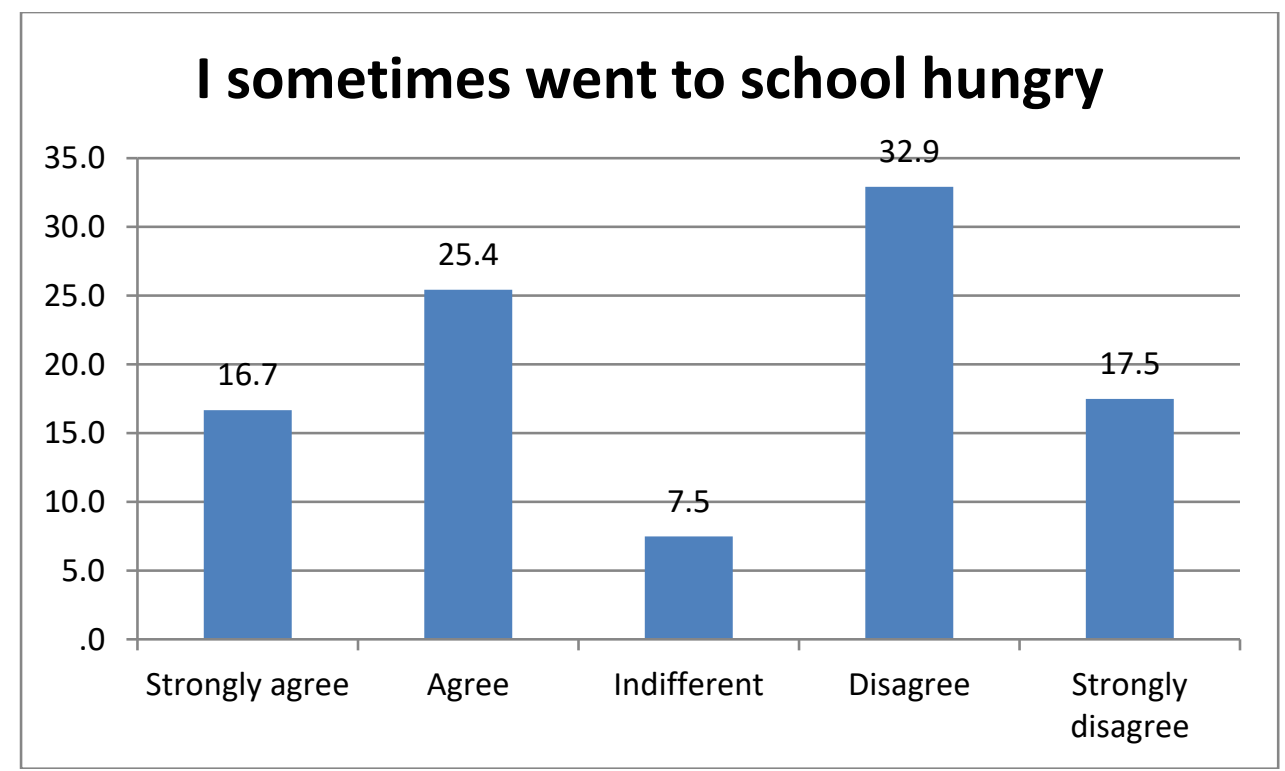

Fig. 8: I Sometimes Went to School Hungry.

\subsection{Working to earn an income}

This observation was captured in the responses of all the participants, they identified income generating activities among AIDS orphans as an indicator for orphans to drop out of school. School key informants agreed $81.5 \%$ of the times that income generating activities amongst AIDS orphans is a strong indicator for school dropout. For upper primary and junior secondary schools AIDS orphans, only $29.1 \%$ of 240 responses showed that an income activity is a strong indicator; this is captured in Figure 8. This is expected as 
they are being looked after by a caregiver. With orphans who already dropped out of school, an income generating activity ranked among the top reasons why they dropped out of schooling. All participants agreed that hunger while sitting in the class leads to many other thoughts in their minds thus reducing concentration on class activities. For example, they may be planning going to motor parks to carry passenger luggage to earn income for food, meaning that school home work is left unattended which over the time can lead to poor performance and eventual dropout.

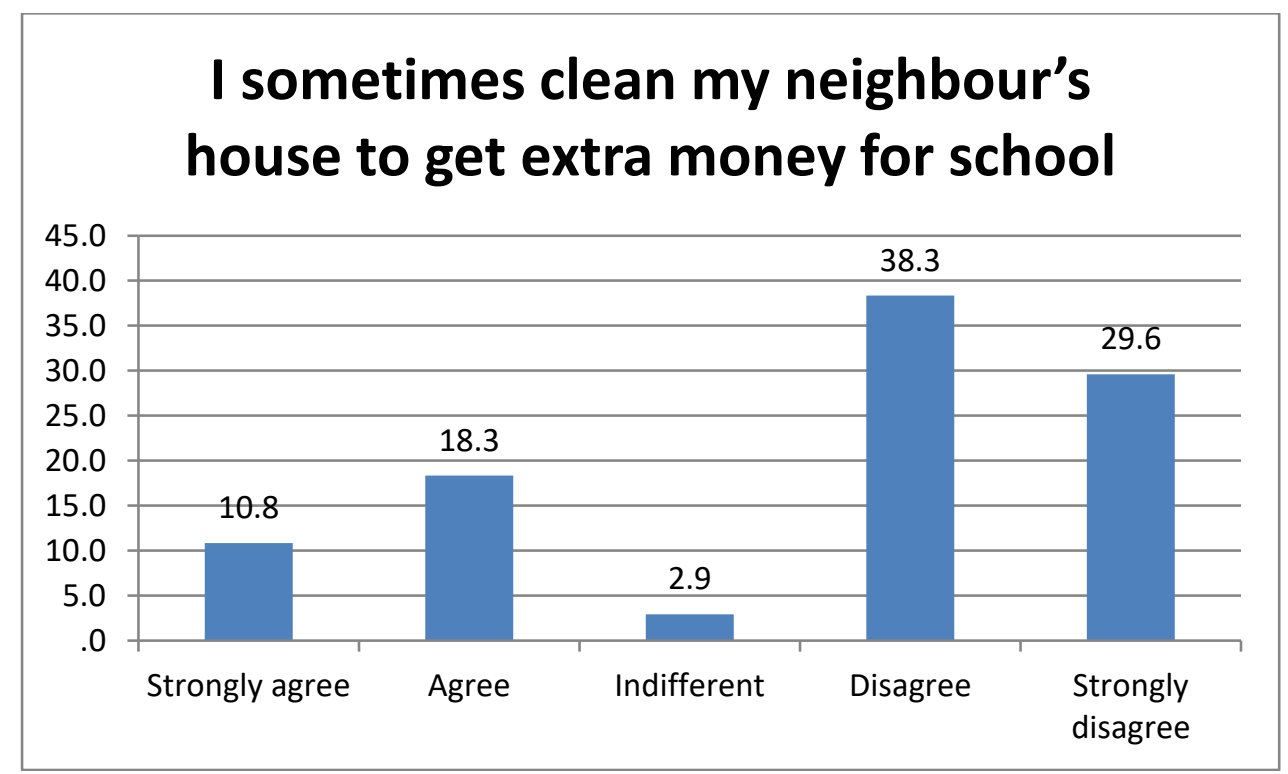

Fig. 9: I Sometimes Clean My Neighbour's House to Get Extra Money for School.

\subsection{Too old for current grade}

One hundred and eighteen out of two hundred and forty orphans, representing $49.2 \%$ of the respondents in grades 7 and 8 were found to be older than 16 years which is above the average age of 15.5 years. Making allowances for late starting and repetition, all leaners should not be older than 15 by the time they reach grade 8 . Though the grade average of 15.5 was already higher than the expected average, 118 AIDS orphans are well above the grade average.

Principals and Life Skills teachers identified old age $66.7 \%$ of the time, that among AIDS orphans, age is an indicator for school dropout. The average age of AIDS orphans in this study who dropped out of school was found to 18 years, which is three years older than the average age of the class when they left school. The older they become, the more complex are their needs and the higher the tendency to drop out of school.

Interview report of two orphans who dropped out of school are presented below as examples of factors leading to school dropout.

The names used in the interview section of this research are not the real names of the respondents. This is done to protect the identity of the respondents.

Pombili is 19 years old male orphan who dropped out of school in 2009 mid-way through grade 9 . His father died when he was 8 and his mother died in 2007. His grandmother took him in along with his younger siblings. Meeting their daily food need became a challenge and Pombili spent more and more time out of school to clean neighbours' home in return for food and small cash. He eventually dropped out of school because of hunger and inability to meet his basic needs.

Pombili remarked that "I was always shy to play with my class mates as they were too young. When we play and one of the kids cried, the teachers always blame me. During holidays I went to look for work in a shop and I decided not to go back to school."

Tuli has faint knowledge of her father who died when she was only six. Her mother died in 2010 when she was in grade 8 and sixteen years old. She never went back to school afterwards. With the assistance of the Life Skills teacher and the school principal, Tuli was registered for government social grant to continue with her studies. Unfortunately Tuli fell pregnant shortly afterwards and the hope of going back to school died away.

\section{Discussion}

4.1. From schools principals and teachers' (key informants) perspective these are reasons accounting for orphans dropping out of school

Faced with an increasing burden of children affected by AIDS, many schools in sub-Saharan Africa are ill equipped to deal orphans. A few are taking modest steps such as establishing "AIDS Clubs," introducing HIV-prevention education, and providing occasional counselling to orphans and other vulnerable children. However, in most cases documented by Human Right Watch, schools proved ill-equipped to address the complex hardships faced by orphaned children.

Human Right Watch and Forster (2000) separately found that Child-headed households were cited as a cause for orphans dropping out of schools. Inability to afford school fees and or school uniform and other prohibitive costs such as textbooks, and examination fees preclude orphaned children from attending school. Key informants agreed $92.6 \%$ of the time that high poverty levels in child headed homes is a high factor contributing to school dropout. Twenty eight percent of Namibians live in poor households, with such high numbers of people in the community living with or being personally affected by HIV coupled with lack of parental support weakens the ability of children to stay in school. Poor household income in AIDS affected homes has direct impact on school attendance. According to Eric, (2003), the effects of poverty are such that in sub-Saharan Africa, children aged five to fourteen who had lost one or both parents were less likely to be in school and more likely to be working more than 40 hours a week than children with both parents.

Consistent among the key informants interviewed, Human Right Watch found that children's first line of defence when their parents or guardians proved unable to support their education were community-based organizations, churches, and women's groups that provided care and support to orphans on extremely limited budgets. There are noble community based interventions, however due to reduction in donor funding, these activities are set to gradually die down. Due to increasing poverty, $81.5 \%$ of the time, principals and 
teachers agreed that orphans having to work to earn a living is a major contributor to school dropout.

Orphans and vulnerable children stand an increased chance of being malnourished and receiving inadequate medical care. A close correlation was reported between child morbidity and the quality of parenting. Children that are malnourished have reduced resistance / defence against many common infectious diseases. Thus when they become sick their school work falls behind and eventually dropped out of school. Thus, poverty and attendant malnutrition and ill health become barriers to attendance and educational quality. Children affected by HIV/AIDS may be subjected to impersonal and abusive child care through exploitative family and community care; poorly chosen and supervised foster care; and long term institution-based rearing. Some care givers favour the education of their own children over the education of orphans in their care. In general, and without considering associated effects such as pre-existing home conditions, separation and bereavement, impersonal and abusive care is associated with a range of psychological disorders, including a reduced capacity for affection and compassion, acting out and more aggressive coping styles Richter,(2004). The participants in this group agreed that domestic problems $(74.1 \%)$ is a contributory factor to orphans dropping out of school.

Linda Richter (2004) observed that, migration has been identified as an important family and community coping mechanism in the face of the HIV/AIDS epidemic. This is consistent (66.7\%) with the participants in the group that relocation of a guardian, especially in Southern Africa contributes to school dropout. Adolescents are particularly affected by migration, children of school going ages might not find schools in their new locations. In some cases the new foster parent is unable or unwilling to sponsor the education of these orphaned children.

\subsection{From learners' perspectives these are some factors or indicators for school dropout among orphans}

Stigma and discrimination associated with the HIV/AIDS epidemic lead to irregularly school attendance and eventual dropout from school. This was found to be consistent with the results obtained from orphans who completed the questionnaire. The stigma associated with HIV/AIDS is causing AIDS affected learners being taunted by their peers. In addition to the emotional difficulty of losing a parent, children orphaned by AIDS are sometimes teased by classmates for being orphans or for "having AIDS". This can lead to peer pressure which can eventually lead to school dropout.

Osborn (2007) reported that increased emotional strain, common amongst the orphaned and vulnerable, may lead to risky behaviours, including exchanging sex for food or shelter and using drugs and alcohol. These are ingredients that proximate school dropout among AIDS orphans. Participants who completed the questionnaire agreed to strongly agree $63.3 \%$ of the time that they feel lonely in their homes in the midst of their foster parents.

Children as caregivers in homes were parents or sibling is living with HIV/AIDS was reported as a factor for school dropout. Human Right Watch documented numerous cases of children dropping out or falling behind in school when their parent or guardian became ill and unable to care for them due to HIV/AIDS. $69.2 \%$ of orphan learners agreed to strongly agree that lack of parental care is a strong motivation to drop out of school. Eric (2003) observed that, the plight of AIDS orphans and their weakened educability due not only to health and nutritional problems but also due to lack of parental support weakens the ability of AIDS orphans to stay in school. Hallfors (2011), observed that providing orphans with a universal daily feeding program; school fees and uniforms, reduced school dropout by $82 \%$ over a period of two years.

Phenomena of stigmatisation and discrimination affect the ability of many orphans or pupils whose families are affected by AIDS to learn. This is in agreement with the findings cited by Kinghorn (2002) that, psychosocial problems due to stress, grief, self-stigmatization, neglect and abuse, social isolation and discrimination affects the learning abilities of orphans. They further pronounced that informants have often noted that these impacts are often worse when children are separated from siblings.

Participants in this research agreed that poor peer relationship is a factor in school dropout. They feel lonely $63.3 \%$, they feel that other children are better than they are $60.4 \%$ and they are not always happy $64.6 \%$. The cumulative effect of these factors is that orphans tend to keep away from other children. This is in conformity with Cluver et al (2007), Bhargava et al. (2005) and Cluver et al. (2008) who separately reported peer relationship difficulties among orphans in sub-Saharan Africa. The difficulties in forging relationships are supported by the findings of other researchers and cited by Cluver et al. (2007) include Nyamukapa et al. (2008) who asserted that evidence suggests that AIDS-orphaned children are at particular risk for psychological distress compared with non-orphans Makame et al. (2002) and Sengendo et al. (1997) found raised rates of depression, Atwine et al. (2005) and Pelton et al. (2005) documented higher levels anxiety in AIDS orphans than non-AIDS orphans.

Cluver (2007) reported on the high post-traumatic stress amongst AIDS orphans. The need for psychosocial support for AIDS orphans cannot be emphasised enough. In a report published by Ministry of Gender Equality and Child Welfare, (2010) psychosocial support was provided to 2114 orphans and vulnerable children in 2010 out of over 120828 registered OVC a mere $1.75 \%$ of children in need. Only 110 OVC were reached with psychosocial support in Oshana region.

Food insecurity (Hunger) at homes was also identified as a major indicator for AIDS orphans to drop out of school. UNDAF and Namibia National Planning Commission and United Nations, (2005) observed that recent figures indicated that some $40 \%$ of Namibians are living below the income poverty line and are exposed to chronic food insecurity. $42.1 \%$ of participants agree to strongly agree that they went to school hungry. High and rising levels of food insecurity compounded the already pathetic conditions of AIDS orphans which can lead to more orphans to drop out of school. Although Namibia is one of the few African countries that provides old age pensions and grants for OVC and for people with disabilities, many do not receive their entitlements, usually due to lack of awareness or geographical or social factors as reported by GRN-Gender, (2007). The effects of hunger on school participation were conveyed in a report by Gender Equality and Child welfare, Namibia National Plan of Action for Orphans and Vulnerable (2007) which says "Feeling hungry and being unable to concentrate at school is a common experience among AIDS orphans and other vulnerable children" Although school feeding programme is in place at some selected schools, they only operational during weekdays and when schools are in session. They are closed during weekends and school holidays.

According to Andrews,(2006), Barnett,( 2006) and UNICEF/UNAIDS (1999) on HIV/AIDS as cited by Edwards (2009), AIDS orphans dropout of school because they cannot pay fees. They have to engage in income generating activities or replace adult labour.

Despite the evident intentions to ensure that AIDS orphans are not deprived of schooling, in practice there are still some OVC who do not attend school. Either because they cannot afford the school development fund contribution, the boarding fees or the school uniform. Working to earn meagre income or because they are required to stay at home to care for a sick parent. In practice, the exemption procedure for AIDS orphans and poor children is rarely used due to lack of awareness as reported by GRN and UNICEF/UNAIDS, (1999)

This is found to be in line with literature findings that showed that AIDS orphans do fall behind their grades when they leave school to mourn their deceased parents. Human Right Watch reported that recent surveys from Kenya, South Africa and Tanzania show that orphans are less likely to be at an age-appropriate grade when they leave school to perform household labor or to grieve their parents' death. Guarcello (2004) concluded that, in many AIDS affected contexts, orphans are less likely to be at their proper educational level than non-orphans of the same age. 
Acquisition of national documents (birth and death certificates) is the major challenges in accessing social services and grants available. Only orphans that are in possession of these documents can access these services.

\section{Conclusion}

From the result of this research, it can be concluded that there are clear indicators or warning signs leading up to the eventual dropping out school amongst orphans and other vulnerable children. The common impacts of HIV/AIDS on orphaned children include deepening poverty, food insecurity, reduced access to health services, increased chances of dropping out of school, deteriorating housing, worsening material conditions, and loss of access to land and other productive assets. Psychosocial distress is another impact on children and families, and it includes anxiety, loss of parental love and nurture, depression, grief, and separation of siblings among relatives to spread the economic burden of their care. The indicators identified in this research are by no means exhaustive but serves as a guide to community members, school authorities and other stake holders in early identification of conditions leading up to school dropout amongst orphans and indeed other children in distress. The role of school principals and Life Skills teachers is paramount in early identification of these signs. The need for psychosocial support for AIDS orphans cannot be emphasised enough. All upper primary, junior secondary school orphans and orphans who dropped out of school agreed that there is need to assist orphans to come to terms with their situation.

\section{Recommendations}

School dropout among orphans in Oshana region requires the combined efforts of all to eradicate. Government of Republic of Namibia (GRN) has laudable policies in place to enhance the education of all orphans. There are always challenges either in the implementation or the scope is too narrow to have the desired effects. Scale up psychosocial support and caring environment; AIDS orphans need help to cope with great challenges like the loss of a parent, separation from siblings. Government and NGOs should help support the healing process and help children build resilience. MGECW provided psychosocial support to 2114 orphans and vulnerable children in 2010 out of over 120828 registered OVC a mere $1.75 \%$ of children in need. There is a clear need to scale up service delivery to reach more needy children in Namibia and Oshana region in particular.

Majority of orphans interviewed are unaware of social grant to support their education. More need to be done in the area of publicising GRN interventions to meet the needs of all needy children. Local counsellors, traditional leaders, the community, schools and all stake holders should be actively involved in the identification and referral of needy children to relevant authorities for support.

Social grant to support educational needs is sometimes diverted to other crucial family needs. GRN may consider sending AIDS orphans and other needy children to a boarding school to guarantee food security.

GRN should offset the economic impact of AIDS on orphans. Exemption from school fees should be monitored and enforced or special indigent scholarships targeting orphans and other needy children should be considered to keep orphans from leaving school for want of resources to pay fees and their general upkeep.

Specific ways in which the GRN and its policies and approaches to schooling and provision of social services to orphans are suggested below: More life skills teachers be employed to ensure early detection of OVC; once identified, OVC should be completely exempt from any form of contribution to school development funds. Foster parents be thoroughly screened before adoptions and where foster parents cannot be found, OVC should be accommodated in GRN hostels and safe home. GRN to facilitate the registration of all OVC, providing them with birth certificates and other national documents through social workers to ensure accessibility to social grants and other services.

\section{Acknowledgments}

The researchers acknowledged the assistance of The Rössing Foundation Ondangwa, Catholic Aids Action and the Ministry of Education, Ondangwa. We wish to thank all the children, and their families, the schools and teachers who participated in the study. Special thanks to Mrs Liina Kuushomwa for assisting in the collection of research materials.

\section{References}

[1] Andrews, G., Skinner D., Zuma, K. (2006). Epidemiology of health and vulnerability among orphans and made vulnerable by HIV in sub-Sahara Africa. AIDS Care, 18(3), 269 - 276 https://doi.org/10.1080/09540120500471861.

[2] Atwine, B., Cantor-Graae, E., \& Bajunirwe, F. (2005). Psychological distress among AIDS orphans in rural Uganda. Social Science and Medicine, 61(3), 555-564. https://doi.org/10.1016/j.socscimed.2004.12.018.

[3] Barnett, T. \& Whiteside, A. (2006). AIDS in the twenty - first century: Disease and globalisation. Palgrave Macmillan Basingstoke.

[4] Bhargava, A. (2005). AIDS epidemic and the psychological well-being and school participation of Ethiopian orphans. Psychology, Health and Medicine, 10(3), 263-275. https://doi.org/10.1080/13548500412331334181.

[5] Biemba G., Beukes C., De Beer I., Mollers M., Lokhorst B., S. J. (2009). Namibia Research Situation Analysis on Orphans and other Vulnerable Children, Final Report 2009. Windhoek.

[6] Burns, N ; Grove, S. K. (2001). The Practice of Nursing Research: Conduct, Critique and Utilisation. 4th Edition: WB Saunders.

[7] Cluver, L., Gardner, F., Operario, D. (2007). Psychological distress amongst AIDS-orphaned children in urban South Africa. Journal of Child Psychology and Psychiatry, 48(8), 755-763. https://doi.org/10.1111/j.1469-7610.2007.01757.x.

[8] Cluver, L., Gardner, F., Operario, D. (2008). Effects of stigma and other community factors on the mental health of AIDS-orphaned children. Journal of Adolescent Health, 42, 410-417. https://doi.org/10.1016/j.jadohealth.2007.09.022.

[9] Cluver, L.; Gardner, F.; Operio, D. (2009). Poverty and psychological health among AIDS-orphaned Children in Cape Town, South Africa. AIDS Care, 21(16), $732 \quad-\quad 741$. https://doi.org/10.1080/09540120802511885.

[10] Edwards - Jauch, L. (2009). The Effects of AIDS-Related mortality on Family Structures in Namibia: Selected case Studies from Namibia AIDS Services organizations. University of Namibia.

[11] Eric, A. (2003). HIV/AIDS: A threat to educational quality in SubSaharan Africa An analytical framework and implications for policy development. Association for the Development of Education in Africa (ADEA).

[12] Forster, G. \& W. J. (2000). A review of current literature of the impact of HIV/AIDS on children in sub-Saharan Africa. AIDS, 14(suppl. 3), S275-S284.

[13] Guarcello, L.; Lyon, S.; Rosati, F.C; Valdivia, C. (2004). the influence of orphan hood on children's schooling and labour: evidence from Sub Saharan Africa. Understanding Children's Work Project working paper series - World BAnk. Washington. Retrieved from http://documents.worldbank.org/curated/en/2004/10/9480193/influence-orphanhood-childrens-schooling-labour-evidence-sub-saharan-africa

[14] Hallfors, D., Cho, H., Rusakaniko, S., Iritiani, B., Mapfumo, J., \& Halpern, C. (2011). Supporting Adolescent Orphan Girls to Stay in School as HIV Risk Prevention: Evidence from a Randomized Controlled Trial in Zimbabwe. American Journal of Public Health, 101(6), 1082 - 1088. https://doi.org/10.2105/AJPH.2010.300042.

[15] Human Rights Watch. (2005.). Letting Them Fail: Government Neglect and the Right to Education for Children Affected by AIDS. $\mathrm{Hu}$ man Rights Watch, 17(13 A).

[16] Osborne, K. (2007). Adolescents: Missing from Programs for the World's Orphans and Vulnerable Children. Advocates for Youth.

[17] Kinghorn, A.; Rugeiyamu, J.; Schierhout, G.; Johnson, S.; Mckay, E.; Ndegwa, D.; Coombe, C.; Mendelsohn, J.; Villet, C. (2002). The Impact of HIV/AIDS on education in Namibia. Windhoek. 
[18] Makame, V.; Ani, C.; and Grantham-McGregor, S. (2002). Providing Orphan Care System in Developing Countries. Retrieved from http://udayancare.org/seminar-journal/aspects_programme.html

[19] Mchombu, C. (2009). Access to Information by Orphans and other Vulnerable Children. Children's Rights in Namibia. Edited by Oliver C.Ruppel, 363- 374.

[20] Ministry of Gender Equality and Child Welfare. (2010). Annual report 2010. Windhoek.

[21] Ministry of Health and Social Services (MoHSS) Namibia and Macro International Inc. (2008). Namibia Demographic and Health Survey 2006-2007. Windhoek - Namibia and Calverton, Maryland, USA.

[22] Namibia National Planning Commission and United Nations. (2005). United Nations Development Assistance Framework 2006-2010 (UNDAF). Windhoek. Retrieved from http://www.unicef.org/about/execboard/files/770-Namibia_UNDAF_-_2006-2010.pdf

[23] Nyamukapa, C., Gregson, S., Lopman, B., Saito S., Watts H. Monasch, R., Jukes, M. C. H. (2008). HIV-associated orphan hood and children's psychosocial distress: Theoretical framework tested with data from Zimbabwe. American Journal of Public Health, 98(1), 133-141. https://doi.org/10.2105/AJPH.2007.116038.

[24] Pelton, J., \& Forehand, R. (2005). Orphans of the AIDS epidemic: An examination of clinical level problems of children. Journal of the American Academy of Child and Adolescent Psychiatry, 44(6), 585591. https://doi.org/10.1097/01.chi.0000157551.71831.57.

[25] Richter, L. (2004). The Impact of HIV/AIDS on the Development of Children. (R. Pharoah, Ed.)A Generation at Risk? HIV/AIDS, Vulnerable Children and Security in Southern Africa. Monograph No 109.

[26] Sato, A. (2012). Do Inequalities in Health Care Utilization in Developing Countries Change When We Take into Account Traditional Medicines? World Development, 40(11), 2275-2289. https://doi.org/10.1016/j.worlddev.2012.03.019.

[27] Sengendo, J; Nambi, J. (1997). The psychological effect of orphan hood: a study of orphans in Rakai district. Health Transit Rev. 7(Suppl. 105), 24.

[28] Ssewamala*, Fred M., Stacey Alicea, William M. Bannon, Jr. and Leyla Ismayilova, M.S.W

[29] A Novel Economic Intervention to Reduce HIV Risks Among School-Going AIDS Orphans in Rural Uganda Journal of Adolescent Health 42 (2008) 102-104

[30] The United Nations Children's Fund (UNICEF). (2005, February) Guide to Monitoring and Evaluation of the national response for children orphaned and made vulnerable by HIV and AIDS. UNICEF, 63

[31] UNAIDS. (2009). Support to NEPAD. Period of Report: July 2008 to June 2009. Retrieved from www.un.org/africa/osaa/2009_un_system/unaids.pdf

[32] United Nations Children's Fund / Joint United Nations Programme on HIV/AIDS (UNICEF/UNAIDS). (1999). Children orphaned by AIDS: Frontline responses from eastern and southern Africa. UNICEF Division of Communication.

[33] Welfare, M. of G. E. and C. (2007). Namibia National Plan of Action for Orphans and Vulnerable, 1. 